\title{
BIOMECHANICAL COMPARISON OF MEDIAL VERSUS LATERAL SIDED PLATING IN FEMORAL FRACTURES
}

\section{COMPARAÇÃO BIOMECÂNICA DE PLACA ÓSSEA MEDIAL VERSUS LATERAL EM FRATURAS DO FÊMUR}

\author{
Firat Al ${ }^{1}$, Bilgehan Tosun ${ }^{2}, T_{\text {amer }}$ Sinmazcelik ${ }^{3}$, Mustafa Ozmen ${ }^{3}$ \\ 1. Golcuk Necati Celik State Hospital, Kocaeli, Turkey. \\ 2. School of Medicine, Kocaeli University, Kocaeli, Turkey. \\ 3. Mechanical Engineering, Kocaeli University, Kocaeli, Turkey.
}

\section{ABSTRACT}

Objective: The aim of the present study was to determine whether the side of application of the plate itself affects the mechanical stability of the fixation. The specific question addressed is whether or not a lateral or medial plate application is biomechanically better, for the treatment of distal diaphysis fractures of the femur. Methods: Stability and stiffness of medial sided plating relative to the conventional lateral sided plating in distal diaphysis of the femur were measured by analyzing axial loading forces leading to implant failure. Sixty synthetic femurs were tested in physiological bending, to calculate the yield and ultimate load to displacement following fixation of distal diaphysis fractures of the femur by either medial or lateral sided plating. Axial loading was applied to samples using a uniaxial testing machine. Results: There was more implant deformation in the lateral sided plating group - a difference with statistical significance. Conclusion: Medial sided plating was found to be as stiff as lateral plating. Medial plating may be a reasonable treatment option that can be used safely in selected cases. Level of Evidence I, Therapeutic Studies Investigating the Results of Treatment

Keywords: Femoral fractures. Bone plates. Stress, mechanical.

\section{RESUMO}

Objetivo: O objetivo deste estudo foi determinar se o lado de aplicação da placa em si afeta a estabilidade mecânica da fixação. A questão específica abordada é se a aplicação da placa lateral ou medial é melhor ou não em termos biomecânicos para o tratamento das fraturas da diáfise distal do fêmur. Métodos: A estabilidade e a rigidez da placa medial com relação à lateral, convencional na diáfise distal do fêmur, foram medidas pela análise das forças de carga axial que levam à falha do implante. Sessenta fêmures sintéticos foram testados em flexão fisiológica, para calcular a tolerância e a carga final para o des/ocamento após a fixação das fraturas diafisárias distais do fêmur com placa medial ou lateral. A carga axial foi aplicada às amostras usando máquina de teste uniaxial. Resultados: Verificou-se maior deformação do implante no grupo de placa lateral - diferença com significância estatística. Conclusão: Constatou-se que a placa medial era tão rígida quanto a lateral. A placa medial pode ser uma opção de tratamento razoável e segura em casos selecionados. Nível de evidência I, Estudos terapêuticos - Investigação dos resultados do tratamento.

Descritores: Fraturas do fêmur. Placas ósseas. Estresse mecânico.

Citation: Al F, Tosun B, Sinmazcelik T, Ozmen M. Biomechanical comparison of medial versus lateral sided plating in femoral fractures. Acta Ortop Bras. [online]. 2018;26(4):265-70. Available from URL: http://www.scielo.br/aob.

\section{INTRODUCTION}

The standard treatment for femoral shaft fractures is intramedullary nailing. ${ }^{1}$ However, a plate osteosynthesis is particularly advantageous in certain situations. Patients with fractures of the proximal or distal shaft, ${ }^{2,3}$ an excessively narrow intramedullary canal, ${ }^{4,5}$ polytrauma patients, ${ }^{6}$ and those with vascular injury associated with femoral fractures ${ }^{7}$ constitute the spectrum of the indications for plate osteosynthesis. From previous investigations, it is known that the tension side of the femur, which is the lateral side, transfers to the anterior side at the distal part. 8,9 Also, the compression side of the femur is the medial aspect proximally, whereas it is the dorsal aspect distally. Based on this information we hypothesized that a plate applied to the lateral or medial side of the femur in distal diaphyseal femoral fractures acts as a compression device. Therefore, we expected similar biomechanical results when the plate was applied either medially or laterally in distal femoral diaphyseal fractures.

To our knowledge, there is no previous study that compares the stability of medial versus lateral femoral plating.

The purpose of this study was to compare the biomechanical behaviors of medial and lateral sided plating in synthetic femurs with fractured distal diaphysis, by analyzing axial loading forces leading to implant failure.

\section{MATERIALS AND METHODS}

Sixty left synthetic composite femurs (Anatomiturk, Kayseri, Turkey) were used to eliminate variations in geometry and mechanical properties such as bone density. The composite femurs were $420 \mathrm{~mm}$ in length from the tip of the greater trochanter to the lateral femoral

All authors declare no potential conflict of interest related to this article.

Work conducted at the Kocaeli University, Kocaeli, Turkey. 
condyle, and $30 \mathrm{~mm}$ in diameter at the mid-diaphysis. The femur was divided into three parts, the proximal femur, diaphysis and distal femur. These parts were delineated as the proximal femur, ending at the distal part of the lesser trochanter, the middle - from this point to the distal metaphysis - and the distal femur, including the distal metaphysis and epiphysis. The diaphysis was further divided into proximal, mid-diaphysis and distal diaphysis. Fracture was created in 30 samples, at the junctional area between the diaphysis and distal metaphysis, $150 \mathrm{~mm}$ (36\%) proximal from the distal joint surface. Fractures were also created in a further 30 samples, just inside the distal $1 / 3$ portion of the diaphysis, $180 \mathrm{~mm}$ (43\%) proximal from the distal joint surface. Thus, the models were categorized into four groups according to their osteotomy levels and fixation methods. Group 1 had an osteotomy $150 \mathrm{~mm}$ from the distal joint surface that was stabilized by medial sided plating (M-15, $\mathrm{n}=15)$; Group 2, $180 \mathrm{~mm}$ osteotomy level - medial sided plating (M-18, $n=15)$; Group 3, $150 \mathrm{~mm}$ osteotomy level - lateral sided plating $(\mathrm{L}-15, \mathrm{n}=15)$ and Group 4, had $180 \mathrm{~mm}$ osteotomy level - lateral side plating $(L-18, n=15)$.

$4.5 \mathrm{~mm}$ low-contoured broad locked dynamic compression plates with 8 holes were bent so that they fit the femoral curve during plate application. The plates were first provisionally applied to the lateral or medial surface of the femur, to dictate the screw position. Screw holes were prepared by drilling centrally through the oval holes of the plate. The plate was then placed either on the medial or lateral side, in neutral mode. After drilling the screw holes, $4.5 \mathrm{~mm}$ tapping was done to facilitate insertion of the screws. Eight cortices were screwed by $4.5 \mathrm{~mm}$ non-locking cortical screws on each side of the simulated fracture. Each model was then anatomically positioned on the uniaxial testing machine (Shimadzu Autograph AG-X, 2007, Kyoto, Japan) to accept load along their mechanical axes (Figure 1). To secure the distal femur, 8 pointed screws were inserted with a jig, into the femoral condyles. The femoral head was also stabilized by a bolt pin to the spherical connection adaptor (Figure 2). After calibrating the testing machine, which was repeated before each test, static tests were performed in compression mode of $10 \mathrm{kN}$ load capacity (Shimadzu AG-X tensile test machine) according to the ASTM D695 ${ }^{10}$ testing standard, with a crosshead velocity of $5 \mathrm{~mm} / \mathrm{min}$. Fifteen synthetic femur specimens for each case were tested. The femurs were loaded progressively at a speed of $5 \mathrm{~mm} / \mathrm{min}$ until the occurrence of a subsequent fracture. During the tests, load-displacement (deformation) curves (Figure 3) were recorded online using the Trapexium X software, and analyzed for the following structural bone properties: yield load (the force causing the first bone damage visible in the load displacement curve, the force at which the load displacement curve broke from linearity), ultimate load (the force causing bone fracture), displacement at yield (defined as the amount of bone deformation at the yield point), and displacement at fracture (deformation at the fracture point). According to the producer, the measurement error of the method was $\pm 1 \%$ of the recorded value. Testing after each experimental period was performed on the same day, by the same operator. The level of the subsequent fracture was determined by the distance from the upper end of the greater trochanter to the fracture line on the lateral cortex. The first $60 \mathrm{~mm}$ from the upper end of the greater trochanter was defined as the proximal part of the femur. Thus, the following $258 \mathrm{~mm}$ femoral diaphysis was divided equally into proximal, mid and distal diaphyseal parts (Figure 4). Some models showed two fracture lines. According to the level and number of subsequent fracture, six groups of subsequent fractures were observed. Implant deformation was also evaluated for plastic deformation of the plate, by inspecting each model.

The configuration of subsequent fracture was separated into four groups, based on the fracture line. A transverse fracture line originating from the

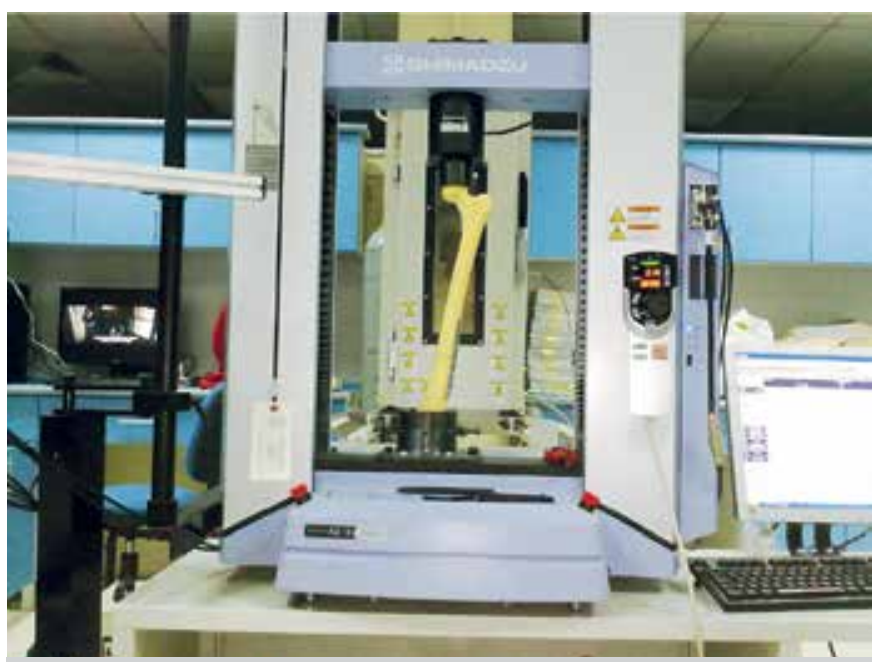

Figure 1. The experimental setup with one specimen is shown. The specimen is positioned anatomically on the uniaxial testing machine.

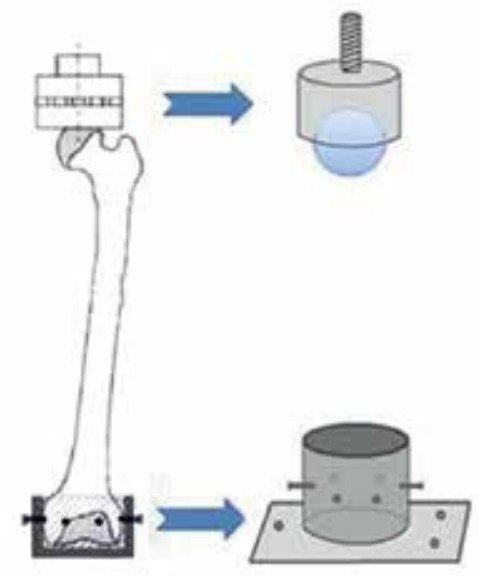

Figure 2. Stabilization of the models by securing the distal femur to the spherical connection adaptor with 8 pointed screws and the femoral head by a bolt pin.

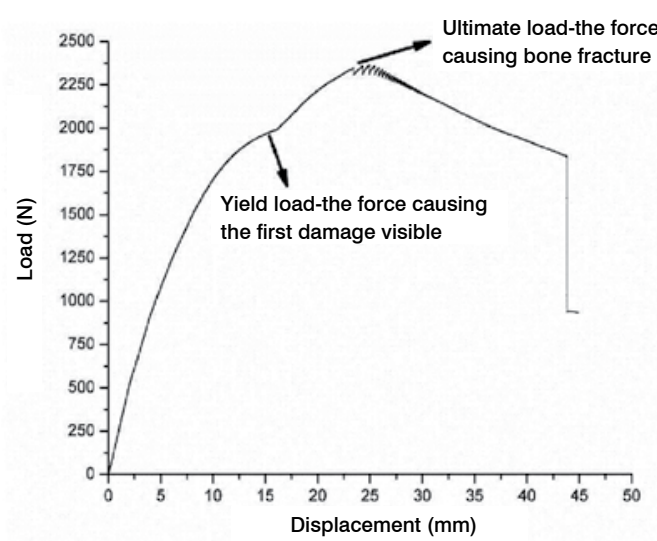

Figure 3. Symbolic load-displacement curve of a synthetic femur specimen. 
lateral cortex that had a reverse oblique pattern on the medial cortex was placed in Group A. Group B consisted of a transverse fractures originating from the lateral cortex that had an oblique pattern on the medial cortex; Group C consisted of transverse fractures originating from the medial cortex that had a reverse oblique pattern on the lateral cortex. Group D had a fracture line related to a screw entry point (Figure 5).

\section{Statistical Methods}

The normality of distribution of the parametric data was checked using the Kolmogorov-Smirnov test. The distribution was accepted as parametric if the results of the Kolmogorov-Smirnov test were not significant. The results for yield and ultimate load to displacement, and comparisons of the subsequent fracture levels between 15

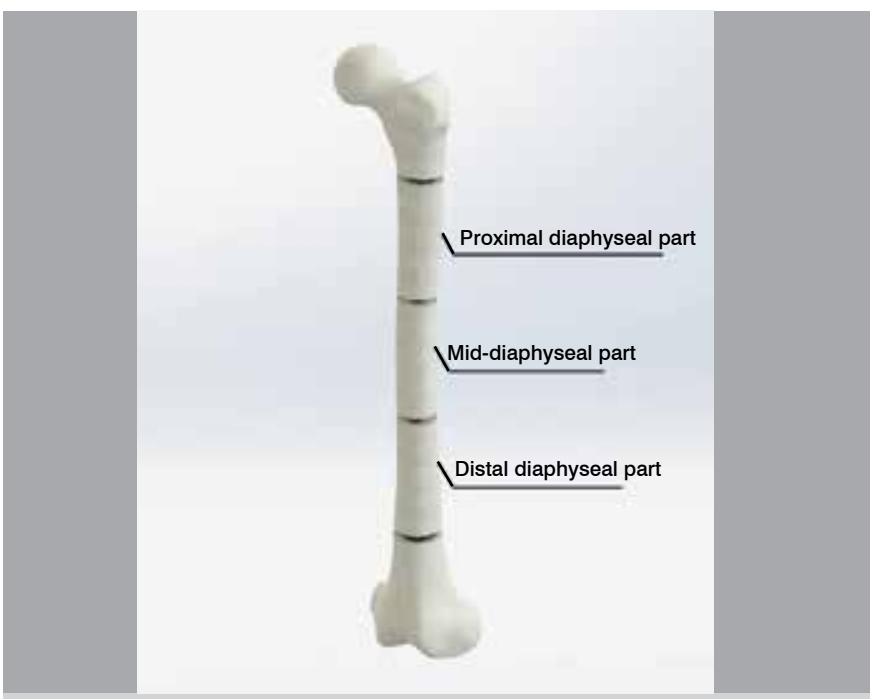

Figure 4. Level of the subsequent fracture. Femoral diaphysis was divided equally into proximal, mid and distal diaphyseal parts.
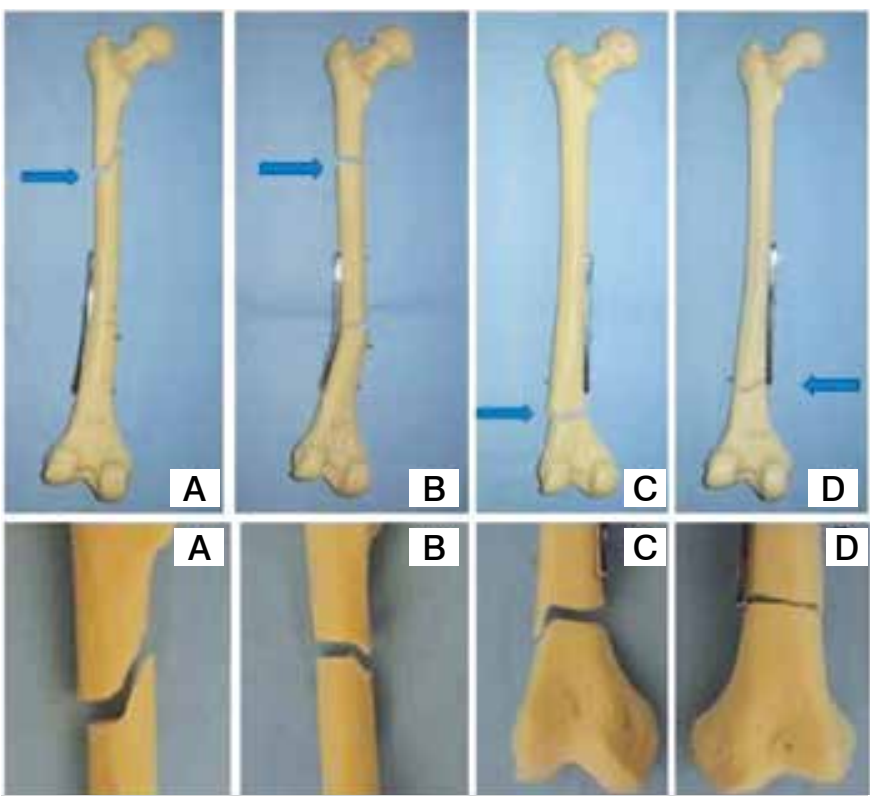

Figure 5. Types of subsequent fractures. A. Transverse fracture line originating from the lateral cortex had a reverse oblique pattern on the medial cortex. B. Transverse fracture originating from the lateral cortex had an oblique pattern on the medial cortex. C. Transverse fracture originating from the medial cortex had a reverse oblique pattern on the lateral cortex. D. Fracture line related to a screw entry point. and $18 \mathrm{~cm}$ osteotomy groups, were subjected to the $t$ test. Multiple pairwise comparisons were performed by the Mann- Whitney $U$ test. The number of subsequent fracture and implant deformations was analyzed by the Chi-Square test. Kruskal-Wallis one-way analysis of variance was used to measure statistical differences between modalities, and $P$ values $<0.05$ were considered significant.

\section{RESULTS}

Fifty-three synthetic composite femurs were available for the current study. Of the sixty models, two models with inexact osteotomy levels and five models with improper data acquisition during testing were excluded from the study.

As the experiment progressed and stiffness increased, the synthetic femurs began to break at different sides in different models.

\section{Stability and Stiffness}

In all the specimens, it was noted that there was a significant difference in yield displacement values between medial sided plating and the conventional lateral sided plating in the distal diaphysis of the femur specimens (Figure 6). The yield displacement values of M15, M18, L15 and 18 were $13.79 \mathrm{~mm}, 14.92 \mathrm{~mm}, 10.75 \mathrm{~mm}$ and 10.18 $\mathrm{mm}$, respectively. The ultimate load values of M15, M18, L15 and 18 were $2826.59 \mathrm{~N}, 2556.61 \mathrm{~N}, 2456.41 \mathrm{~N}$ and $2326.1 \mathrm{~N}$, respectively. The ultimate load values of the medial sided plating specimens at osteotomy levels 15 and 18 were higher than those of the lateral sided plating specimens (Table 1). Yield $\left(P^{15}=0.409, P^{18}=0.427\right)$ and ultimate loads to displacement $\left(P^{15}=0.357, P^{18}=0.701\right)$ values were not statistically significantly different between groups.

\begin{tabular}{|c|c|c|c|c|c|}
\hline & 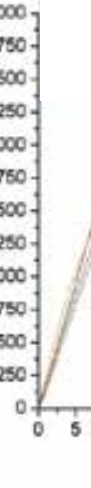 & $\begin{array}{l}15 \quad 20 \quad 25 \\
\text { Displa }\end{array}$ & 3540 & 50556068 & $\begin{array}{l}\text { M15 } \\
\text { L15 } \\
\text { M18 } \\
\text { L18 }\end{array}$ \\
\hline \multicolumn{6}{|c|}{$\begin{array}{l}\text { Figure 6. Load-displacement curves according to four different types of } \\
\text { fixation and osteotomy levels. }\end{array}$} \\
\hline \multicolumn{6}{|c|}{$\begin{array}{l}\text { Table 1. Values for mean yield load, ultimate load and displacement at } \\
\text { fracture according to the type of fixation and osteotomy levels. }\end{array}$} \\
\hline & Group & $\begin{array}{c}\text { Number of } \\
\text { specimen }\end{array}$ & $\begin{array}{c}\text { Mean } \\
\text { values }\end{array}$ & $\begin{array}{c}\text { Standard } \\
\text { deviation }(+)\end{array}$ & $\begin{array}{c}\text { Standard } \\
\text { deviation (+) }\end{array}$ \\
\hline \multirow{4}{*}{ Yield load (N) } & M15 & \multirow{4}{*}{15} & 2333.58 & 65 & 60 \\
\hline & $\mathrm{L} 15$ & & 1627.32 & 80 & 70 \\
\hline & M18 & & 1978.45 & 45 & 45 \\
\hline & L18 & & 1778.31 & 55 & 70 \\
\hline \multirow{4}{*}{$\begin{array}{l}\text { Ultimate } \\
\operatorname{load}(\mathrm{N})\end{array}$} & M15 & \multirow{4}{*}{15} & 2826.59 & 85 & 90 \\
\hline & L15 & & 2456.41 & 70 & 75 \\
\hline & M18 & & 2556.61 & 80 & 65 \\
\hline & L18 & & 2326.1 & 60 & 55 \\
\hline \multirow{4}{*}{$\begin{array}{l}\text { Displacement } \\
\text { at fracture }\end{array}$} & M15 & \multirow{4}{*}{15} & 21.40 & 0.25 & 0.5 \\
\hline & L15 & & 24.80 & 0.3 & 0.6 \\
\hline & M18 & & 24.45 & 0.4 & 0.3 \\
\hline & L18 & & 60.2 & 0.9 & 0.85 \\
\hline
\end{tabular}




\section{Features of Subsequent Fracture}

The samples demonstrated at least one subsequent fracture. Subsequent fractures mostly occurred at the proximal femoral region. A single subsequent fracture was seen in 41 samples (77.3\%), while 12 samples (22.7\%) showed two subsequent fractures. The second fracture was always at the first or eighth screw hole (91.7\%). In the models with two subsequent fractures, the mean distance from the greater trochanter to the first fracture line was $164.6 \mathrm{~mm}$, while the distance to the second fracture line was 289.5. Subsequent fractures seen in lateral sided plating ( $\mathrm{L} 15$ and L-18) group demonstrated a predilection for the proximal femur. In the group of medial sided plating (M-15 and $\mathrm{M}$-18), subsequent fractures mostly occurred in the mid-diaphyseal region (Table 2). There were no statistically significant differences in terms of the number and location of subsequent fractures.

For the subsequent fractures, a transverse fracture line originating from the lateral cortex that had a reverse oblique pattern on the medial cortex was the most frequent fracture configuration (58.5\%). This was followed by a transverse fracture originating from lateral cortex with an oblique pattern on the medial cortex (13.2\%); a transverse fracture originating from the medial cortex with a reverse oblique pattern on the lateral cortex (1.9\%), and a fracture line at a screw hole (26.4\%), respectively.

\section{Implant Deformation}

Of the 53 synthetic femurs, plastic deformation of the plate was seen in 21 samples (39.6\%) after accomplishing axial loading. Surprisingly, these deformed implants, with the exception of one at the $18 \mathrm{~cm}$ osteotomy, all belonged to lateral sided plating group (Figure 7). The implant deformation rate was $71.4 \%$ in the L15 group, and $76.9 \%$ in the L18 group (Table 3). There was more implant deformation in lateral sided plating group, with statistical significance $(P<0.0001)$.

Table 2. Subsequent fracture location. Lateral sided plating group has a predilection for the proximal femur. In the group of medial sided plating, subsequent fractures mostly occurred in the mid-diaphyseal region.

\begin{tabular}{c|c|c|c|c}
\hline Group & Sample size & Mean $(\mathrm{mm})$ & $\begin{array}{c}\text { Standard } \\
\text { deviation }\end{array}$ & $\begin{array}{c}\text { Fracture } \\
\text { location }\end{array}$ \\
\hline M15 & 13 & 211.69 & 111.70 & Mid-diaphyseal \\
\hline L15 & 14 & 142.00 & 70.31 & $\begin{array}{c}\text { Proximal } \\
\text { diaphyseal }\end{array}$ \\
\hline M18 & 13 & 169.69 & 70.56 & Mid-diaphyseal \\
\hline L18 & 13 & 126.23 & 26.24 & $\begin{array}{c}\text { Proximal } \\
\text { diaphyseal }\end{array}$ \\
\hline
\end{tabular}

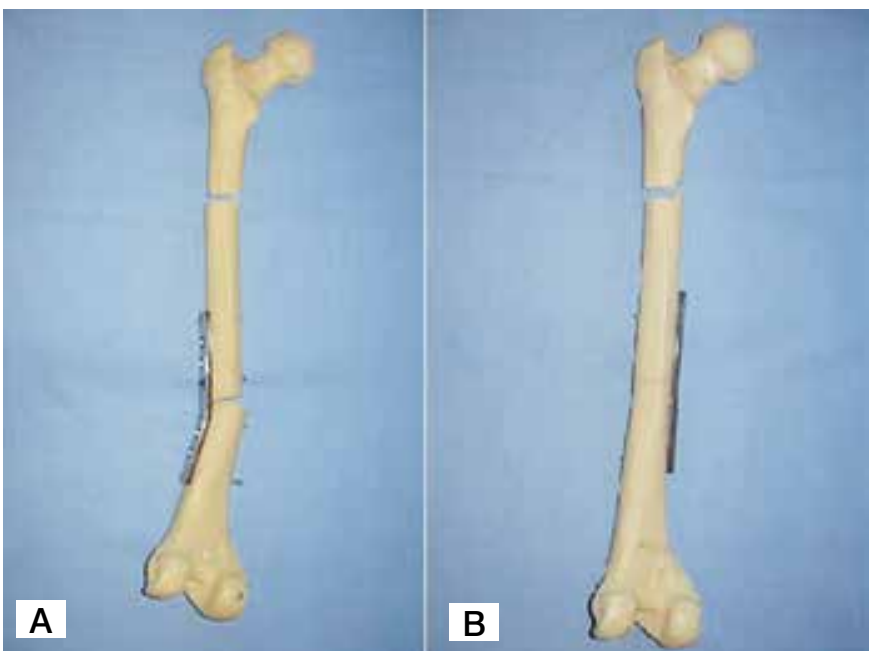

Figure 7. Implant deformation in the lateral sided plating group. B. Excellent plate contour in the medial sided plating group.

Table 3. Implant deformation according to the groups. All deformed
implants, except for one belong to lateral sided plating group.
\begin{tabular}{c|c|c|c|c} 
Group & \multirow{2}{*}{ Sample size } & Implant deformation & $\begin{array}{c}\text { Implant } \\
\text { deformation }\end{array}$ \\
\cline { 3 - 4 } & & - & + & $0 \%$ \\
\hline M15 & 13 & 13 & 0 & $71.4 \%$ \\
\hline L15 & 14 & 4 & 10 & $7.7 \%$ \\
\hline M18 & 13 & 12 & 1 & $76.9 \%$ \\
\hline L18 & 13 & 3 & 10 & \\
\hline
\end{tabular}

\section{DISCUSSION}

For fractures of the femoral diaphysis, from the lesser trochanter to $10 \mathrm{~cm}$ proximal to the knee joint, locked intramedullary nailing is the standard treatment modality. However, a plate osteosynthesis is particularly advantageous in certain situations. Patients with an excessively narrow intramedullary canal, ${ }^{4,5}$ polytrauma patients, ${ }^{6}$ and those with vascular injury associated with the femoral fractures ${ }^{7}$ constitute good indications for plate osteosynthesis.

Orthopaedic surgeons tend to attach a lateral plate in almost all cases, due to the simplicity of the procedure, and better preservation of the muscles, nerves and vascularization. Medial sided femoral plating has been reported less frequently for the clinical management of lower limb deformities after correction osteotomies. ${ }^{11-15}$ Despite its occasional use, no clinical and mechanical information on this technique in the trauma setting has been reported. From a mechanical standpoint, our results showed no significant difference between lateral and medial sided plating by means of axial loading.

Superficial femoral vessels are injured with greater frequency than common femoral vessels in femoral fractures. ${ }^{16}$ In the setting of femoral fractures associated with vessel injury, the vessels should be explored via a posteromedial approach to the femur. A posteromedial approach allows medial plating to the distal femur diaphyseal fracture. Therefore, fractures located in the distal diaphyseal region were used for the study.

The loading model described by Koch is used to investigate the biomechanical behavior of the femur models. ${ }^{17}$ Koch carried out a detailed analysis of a femur without muscles and soft tissues to show that the lateral side of the femur was in tension and the medial side was in compression. An analysis of Koch's model by Fetto et al. ${ }^{18}$ revealed that the tensile load on the lateral side changed to a compressive load when the actions of the iliotibial band and vastus lateralis- gluteus complex were included. It was the contribution of Pauwels ${ }^{19}$ that introduced the tension band principle, which states that tensile forces on the convex side of a curved tube can be converted to compressive forces by applying an implant to the convex side of the tube. The tension band principle works when there is anatomic apposition of cortices on the opposite side of application of plate. It does not apply when there is comminution on the opposite cortex or in comminuted fractures. Ascenzi et al. ${ }^{20}$ had demonstrated the different collagen orientation within the femoral diaphysis as to the aspect of compression and tension. This principle was strongly propagated by AO. They offered the typical application of this principle by fixing a plate to the femur on the lateral side of the diaphysis. ${ }^{21}$ However, Cordey et al. speculated that the tension side of the femur, which is at the lateral aspect, particularly at the proximal part, turns around the anterior aspect distally. The compression side of the femur also turns from the medial to the posterior aspect distally. ${ }^{8,9}$ This means that when a plate is fixed to the lateral aspect of the distal femur, this plate may not be applied according to the tension 
band principle. A plate that is fixed to the lateral or medial side of the distal femur may act as a compression device, due to the rotation of the axis, in order to produce tension at the anterior aspect and compression at the posterior aspect within the distal diaphysis of the femur.

Cordey et al. ${ }^{9}$ evaluated the strain within the diaphysis during axial loading. They also measured high bending forces and stresses in the diaphysis, when the tension band effect of the iliotibial tract has been neglected. High bending forces were explained by the higher bending moment in the frontal plane. Because effect of the soft tissues on stability and stiffness was not taken into account, subsequent fractures mostly occurred at the proximal femoral region in the lateral sided plating group. The lack of muscle attachments will probably have a dramatic effect on the secondary fracture pattern.

The plates applied to the lateral side of the femur have more stress, as the bending moment experienced by the plate is directly related to the force of application and the distance of the implant from the force of application. The line of application of the weight-bearing force is approximately 1 to $2 \mathrm{~cm}$ distant from the force of application with plate fixation of the femur. Stress applied to the femur passes directly up the femoral shaft and bypasses the femur by means of absorption of stress through the distal screws into the plate, and back into the femur through the proximal screws. ${ }^{22}$ The placement of the plate relative to the loading direction will determine the proportion of the load supported by the plate. By medializing the plate fixation, some of the load supported by the plate will be shared by bone fragments (Figure 8). Thus, lateral sided plates were the only ones that experienced plastic deformation. This is because the loading path was more medial, meaning that the lateral plates were subjected to bending that the medial plates were spared.

The variability of cadaveric specimens has always been a problem, requiring enormous sample sizes to obtain satisfactorily significant results. For this reason, synthetic femurs were chosen for this study. Synthetic femurs have a standardized geometry, very small specimen to specimen variability, and material behavior approximating that of bone. ${ }^{23}$ Schoenfeld et al. looked at the pullout strength and load to failure properties of self-tapping cortical screws in synthetic and cadaveric environments representing healthy and osteoporotic bone, and found that although the trends may be similar, screw performance in the synthetic models was markedly different from that in cadavers. ${ }^{24}$ As distal diaphyseal femoral fractures are mostly seen in young adults, due to high energy related traumas, part of the experiment was to represent bone quality by the synthetic composite femurs. Therefore, we used a thoroughly validated model of human femur to remove these undesirable characteristics seen in cadaveric specimens.

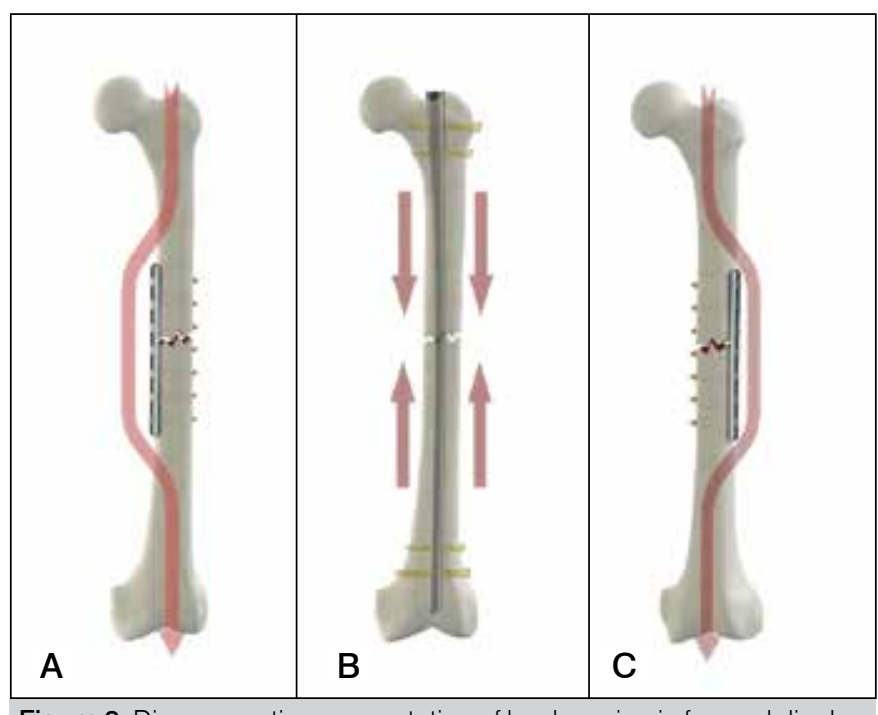

Figure 8. Diagrammatic representation of load sparing in femoral diaphyseal fractures. A. Medial femoral plating. By medializing the plate fixation, some of the load supported by the plate is shared by bone fragments. B. Intramedullary nailing. C. Traditional lateral femoral plating

In a situation of a vascular injury, the first step is to shunt the limb, followed by rapid external fixation, then vascular repair, immediately followed by the definitive fixation, provided the patient is well enough. A midlateral approach is traditionally used for femoral fractures in which plates and screws are used for the fixation. In such cases, especially with a vascular injury, this procedure requires two separate incisions; a medial approach for the vascular repair, and a lateral approach for the fracture treatment. The soft tissue disruption associated either with open reduction and internal fixation, or with external fixation, may be reduced by using a single medial approach that allows bone stabilization under direct visualization of the repaired vessels.

In the current study, medial sided plating constructs were comparable in stiffness to the conventional lateral sided plating constructs. In selective cases, medial plating may be a reasonable treatment option that can be used safely.

In this study, only the primary fixation strength in a composite femur model was tested by axial loading. Torsional testing could also have been tested. It is also unknown how the results of this study translate to actual bone healing rates, loss of correction, and clinical outcome. As a limitation of our study, the failure of fixation rarely occurs with one-time high level loading. It would have been more appropriate to perform the testing in cyclic loading.

AUTHORS' CONTRIBUTIONS: Each author made significant individual contributions to this manuscript. FA (0000-0003-4208-8162)*and BT (0000-0002$0184-8850)^{*}$ were the main contributors in the drafting of the manuscript. FA and Mustafa Ozmen (0000-0001-6795-2856)* evaluated the data from the statistical analysis. FA, BT and TS (0000-0002-3276-5820)* performed the literature search and review of the manuscript, and contributed to the intellectual concept of the study.. *ORCID (Open Researcher and Contributor ID).

\section{REFERENCES}

1. Winquist RA, Hansen ST Jr, Clawson DK. Closed intramedullary nailing of femoral fractures. A report of five hundred and twenty cases. J Bone Joint Surg Am. 1984;66(4):529-39.

2. Krettek $C$, Schandelmaier $P, T$ scherne $H$. [Distal femoral fractures. Transarticular reconstruction, percutaneous plate osteosynthesis and retrograde nailing]. Unfallchirurg. 1996;99(1):2-10.

3. Kinast C, Bolhofner BR, Mast JW, Ganz R. Subtrochanteric fractures of the femur. Results of treatment with the 95 degrees condylar blade-plate. Clin Orthop Relat Res. 1989;(238): 122-30.

4. Sink EL, Hedequist D, Morgan SJ, Hresko T. Results and technique of unstable pediatric femoral fractures treated with submuscular bridge plating. J Pediatr Orthop. 2006;26(2):177-81 
5. Kanlic EM, Anglen JO, Smith DG, Morgan SJ, Pesántez RF. Advantages of Submuscular Bridge Plating for Complex Pediatric Femur Fractures. Clin Orthop Relat Res. 2004;426:44-51.

6. Apivatthakakul T, Chiewcharntanakit S. Minimally invasive plate osteosynthesis (MIPO) in the treatment of the femoral shaft fracture where intramedullary nailing is not indicated. Int Orthop. 2009;33(4):1119-26.

7. Sher $\mathrm{MH}$. Principles in the management of arterial injuries associated with fracture/dislocations. Ann Surg. 1975;182(5):630-4.

8. Hommel GJ, Lobrano C, Ogden AL, Mukherjee DP, Anissian L, Marymont JV A quantitative analysis of tension band plating of the femur diaphysis. Arch Orthop Trauma Surg. 2011;131(10):1325-30.

9. Cordey J, Borgeaud M, Frankle M, Harder Y, Martinet O. Loading model for the human femur taking the tension band effect of the ilio-tibial tract into account. Injury. 1999;30 Suppl 1:26-30.

10. ASTM D695-10. Standard Test Method for Compressive Properties of Rigid Plastics. ASTM. 2008;8:1-8

11. Backstein D, Morag G, Hanna S, Safir O, Gross A. Long-term follow- up of distal femoral varus osteotomy of the knee. J Arthroplasty. 2007;22(4 Suppl 1):2-6.

12. Preston CF, Fulkerson EW, Meislin R, Di Cesare PE. Osteotomy about the knee: applications, techniques, and results. J Knee Surg. 2005;18(4):258-72.

13. Wang JW, Hsu CC. Distal femoral varus osteotomy for osteoarthritis of the knee. J Bone Joint Surg Am. 2005;87(1):127-33.

14. Aglietti $P$, Menchetti PP. Distal femoral varus osteotomy in the valgus osteoarthritic knee. Am J Knee Surg. 2000;13(2):89-95.

15. McDermott AG, Finkle JA, Farine I, Boynton EL, MacIntosh DL, Gross A. Distal femoral varus osteotomy for valgus deformity of the knee. J Bone Joint Surg Am. 1988;70(1):110-6.

16. Asensio JA, Kuncir EJ, García-Núñez LM, Petrone P. Femoral vessel injuries: Analysis of factors predictive of outcomes. J Am Coll Surg. 2006;203(4):512-20.

17. Koch JC. The laws of bone architecture. Am J Anat. 1917;21(2):177.

18. Fetto J, Leali A, Moroz A. Evolution of the Koch model of the biomechanics of the hip: clinical perspective. J Orthop Sci. 2002;7(6):724-30.

19. Pauwels F. Die Bedeutung der Bauprinzipien des Stütz und Bewegungsapparates für die Beanspruchung der Röhrenknocken. Z Anat Entw Gesch. 1948;114:129-66.

20. Ascenzi A, Improta S, Portigliatti Barbos M, Carando S, Boyde A. Distribution of lamellae in human femoral shafts deformed by bending with inferences on mechanical properties. Bone. 1987;8(5):319-25.

21. Müller ME, Allgöwer M, Schneider R, Willenegger H. Manual of internal fixation. $2^{\text {nd }}$ ed. Berlin: Springer, 1979.

22. Mooney V, Claudi B. Fractures of the shaft of the femur. In: Fractures. Rockwood, CA. Jr.; Green, DP., eds. Philadelphia, JB Lippincott; 1975.p.1093.

23. Papini M, Zdero R, Schemitsch EH, Zalzal P. The biomechanics of human femurs in axial and torsional loading: comparison of finite element analysis, human cadaveric femurs, and synthetic femurs. J Biomech Eng 2007;129(1):12-9.

24. Schoenfeld AJ, Battula S, Sahai V, Vrabec GA, Corman S, Burton L, et al. Pullout strength and load to failure properties of self-tapping cortical screws in synthetic and cadaveric environments representative of healthy and osteoporotic bone. J Trauma. 2008;64(5):1302-7. 